\title{
A "DURA" E O "DESENROLO": EFEITOS PRÁTICOS DANOVALEI DE DROGAS NO RIO DE JANEIRO
}

\author{
Carolina Christoph Grillo
}

\author{
Frederico Policarpo
}

\author{
Marcos Veríssimo
}

\section{RESUMO}

O artigo apresenta uma análise dos efeitos da nova lei de drogas sobre a repressão legal ao consumo de substâncias ilícitas e o processamento formal dos casos encaminhados ao sistema de justiça criminal. Buscou-se compreender as práticas dos atores envolvidos com o controle social ou legal do uso de drogas e elucidar as dinâmicas das negociações envolvidas no processo de incriminação dos usuários, à luz do debate em torno das mudanças trazidas pelo novo diploma legal. Observou-se uma redução dos números de casos que entram no sistema como uso de drogas, o que não se explicaria somente pela mudança na lei, mas pela interpretação de que esse crime teria se descaracterizado. Argumentamos que o descaso com o processamento legal desse tipo de crime teria deixado sua administração a cargo dos policiais militares que fazem o policiamento ostensivo nas ruas, que ganharam um aval implícito para negociar o encaminhamento ou não do usuário para a delegacia e até mesmo influenciar o tipo penal em que ele será classificado. A imprecisão dos critérios legais para distinguir entre usuários e traficantes, somada à imensa disparidade entre as penas previstas para esses crimes - acentuada pela nova lei -, contribuiria para a negociação informal da maior ou menor punição dos indivíduos e reificaria os estereótipos policiais, favorecendo a arbitrariedade. Tal indefinição não resultaria de uma imprecisão da lei, mas da impossibilidade empírica de realizar-se um recorte preciso entre essas classificações.

PALAVRAS-CHAVE: uso de drogas; nova lei de drogas; administração institucional de conflitos; controle social; mercadoria política.

\section{INTRODUÇÃO}

A nova Lei de Drogas, a Lei n. 11 343/06, em vigor desde outubro de 2006, teve como uma de suas principais mudanças - ou pelo menos a mais alardeada pela mídia - a extinção da possibilidade de pena de prisão para os usuários de drogas, apesar de manter todos os demais procedimentos legais para o tratamento desses casos, que permaneceram classificados como crime. As instituições responsáveis pela administração legal dos casos de uso de drogas continuaram, portanto, as mesmas de antes.

No intuito de analisar o impacto desse novo diploma legal na relação entre o sistema de justiça criminal e os usuários de drogas, foi desenvolvida, entre novembro de 2007 e julho de 2009, uma pesquisa intitulada "O uso de drogas e o sistema de justiça criminal"1, na qual este artigo baseiase. Procurou-se compreender como a reformula-

$\overline{1}$ O projeto de pesquisa, coordenado pelo Professor ção da legislação sobre as drogas influenciou, na prática, os modos de administração dos conflitos relacionados ao uso das mesmas, focando a princípio as instituições por onde passavam os usuários, de maneira a visualizar o fluxo do processo social e institucional a que eram submetidas as pessoas flagradas usando drogas. $\mathrm{O}$ contraste com outro trabalho anterior sobre o tema (POLICARPO, 2007) permitiu a observação das possíveis mudanças e continuidades a partir da nova lei.

A proposta inicial foi verificar, nas diferentes esferas, a atuação dos operadores do sistema de justiça criminal com relação ao uso de drogas: na Polícia Militar, responsável pela grande maioria dos registros de flagrantes; na Polícia Civil, que tipifica a ação como crime, encaminhando os

Roberto Kant de Lima, foi elaborado atendendo ao edital do Programa de Treinamento e Capacitação Técnica da Fundação Carlos Chagas Filho de Amparo à Pesquisa do Estado do Rio de Janeiro (TCT Faperj 8/2007). 
casos à Justiça; e nos Juizados Especiais Criminais, que julgam os acusados. Contudo, no desenrolar da pesquisa percebeu-se a alta relevância das falas e práticas dos consumidores de drogas para analisar o contexto empírico sobre o qual as leis propõem-se a agir.

A pesquisa foi desenvolvida por meio de três diferentes inserções etnográficas: primeiramente, em três Juizados Especiais Criminais (JECrim), situados na cidade do Rio de Janeiro, onde são julgados os crimes de menor potencial ofensivo ${ }^{2}$ e, entre eles, os casos de uso de drogas; em seguida, em uma delegacia situada na zona norte da cidade do Rio de Janeiro; por fim, com usuários de crack no chamado Complexo do Salgueiro, no município de São Gonçalo, zona metropolitana do Rio de Janeiro.

Também foram realizadas entrevistas com policiais militares e com pessoas de classe média, usuárias de diferentes drogas. Por meio dessas diferentes etnografias e das entrevistas, pretendeuse observar de que modo a lei é atualizada na prática, isto é, como efetiva-se o controle legal sobre o uso de substâncias ilícitas.

\section{DA ESFERA JUDICIAL OFICIAL À ESFERA POLICIAL OFICIOSA}

Com base em entrevistas com juízes, promotores, defensores e conciliadores do JECrim, percebeu-se que eles passaram a sentir-se desobrigados de atuar com relação ao crime por uso de drogas, percebendo essa infração como fora da competência da Justiça Criminal. Eles também alegavam que a ausência da possibilidade de encarceramento teria esvaziado as garantias de cumprimento, pelos infratores, das medidas alternativas determinadas em juízo. Tais constatações foram ilustradas pelo seguinte trecho de uma entrevista realizada com uma juíza: "A nova lei de drogas é descriminalizadora na prática, mas não na lei, porque a Igreja Católica e a Evangélica não quiseram bancar. Mas como não tem pena, não tem crime. Eu vou fazer igual a uma amiga: na intimação, vai junto a advertência. Eu não vou chamar ninguém aqui pra dizer: "filhinho, não use drogas'. Eu sou contra, mas vou ter que fazer isso".

Além disso, em consulta às pautas das audiências das unidades dos JECrim que freqüentamos, notamos uma significativa diminuição nos julgamentos pelos crimes de uso de drogas. Com o objetivo de verificar se essa mudança estava ocorrendo de maneira pontual apenas nesses juizados, ou se ela refletia-se em todo o sistema de justiça criminal de maneira sistemática, trabalhamos com os dados de registro de ocorrência produzidos pelo Instituto de Segurança Pública do Estado do Rio de Janeiro (ISP-RJ). Os gráficos abaixo mostram a incidência anual das ocorrências registradas de posse ou uso de drogas no estado do Rio de Janeiro, entre os anos de 2003 e 2008.

\section{GRÁFICO 1 - POSSE OU USO DE DROGAS NO ESTADO DO RIO DE JANEIRO (2003-2008)}

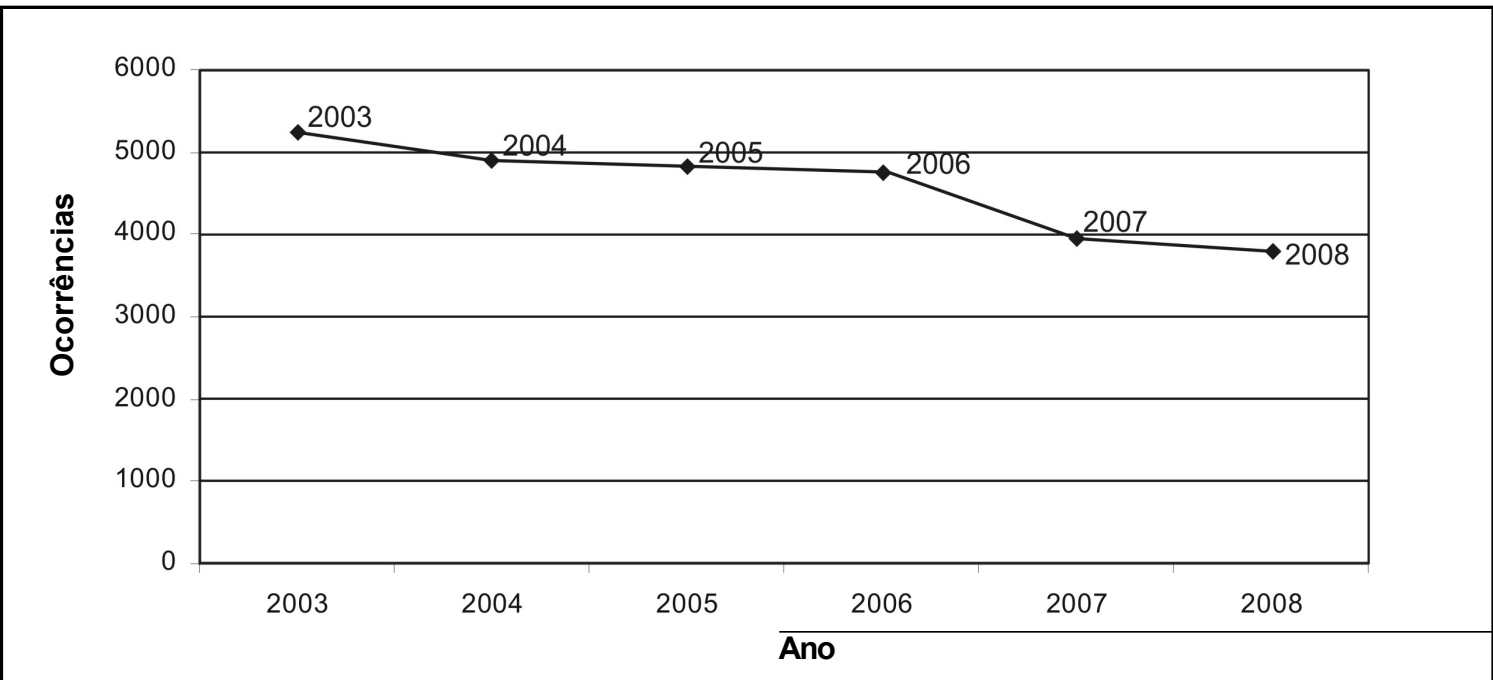

\section{FONTE: ISP-RJ (2011)}

2 Quando a Lei n. 9 099, que regulamenta os JECrim estaduais, foi criada em 1995, o conceito de crime de menor potencial ofensivo era de até um ano. Mas, com a criação, em 2001, dos JECrim federais por meio da Lei n. 10259 , esse conceito foi ampliado para até dois anos, incluindo o uso de drogas. 
Como é possível constatar, está em curso uma queda nos registros de ocorrência por flagrante de uso de drogas, desde a implementação da nova lei, ao final de 2006. Ao somarem-se os dados mensais referentes aos 24 meses anteriores à mudança - novembro de 2004 a outubro de 2006 - e os posteriores - novembro de 2006 a outubro de 2008 - percebeu-se que a incidência foi $20 \%$ menor no período após a nova lei.

Essa diminuição não pode ser explicada simplesmente pela mudança na lei, pois foi mantida a obrigatoriedade de que os usuários de drogas surpreendidos em flagrante sejam conduzidos à delegacia distrital mais próxima, onde devem assinar um Termo Circunstanciado, comprometendo-se a comparecer numa audiência do JECrim. A redução do processamento legal de casos de uso de drogas levou-nos a supor que a administração dos mesmos teria ficado sob a responsabilidade da Polícia Militar, instituição que realiza o policiamento ostensivo, atuando na ponta do sistema de justiça criminal. $\mathrm{O}$ aparente descaso do poder Judiciário com a redução da entrada de usuários no sistema parece ter legitimado a atuação informal dos policiais militares que, já desde antes da nova lei, negociavam o encaminhamento, ou não, dos indivíduos flagrados para a delegacia.

Não há nenhuma novidade em policiais militares "achacando" usuários de drogas, assim como ocorre com alguns infratores das regras de trânsito, de quem é cobrada a popularmente chamada "cervejinha" ou "cafezinho". Motoristas cuja documentação não foi paga, por exemplo, podem negociar a isenção da multa, quando abordados nas chamadas "blitz" ou "duras", principalmente nas operações extraoficiais ${ }^{3}$. Nessas mesmas "duras", ocorre também a revista dos indivíduos suspeitos que, quando surpreendidos com drogas, freqüentemente pagam o tributo informal (digamos assim) para serem liberados, chegando até mesmo a irem, em companhia de um policial, ao caixa-eletrônico para sacar mais dinheiro, conforme foi-nos narrado. Observamos também que consumidores de maconha queixam-se dos policiais militares que "dão o bote" para extorqui-los nos lugares afastados onde eles costumam fumar seus

3 Aquelas em que não está presente um oficial superior. "baseados" (cigarros de maconha), como trilhas e mirantes, como nos contou J.: "Eu nem vou mais nas cachoeiras do Horto ou do Jardim Botânico, porque além do risco de ser assaltada, o pior são os policiais que ficam tentando pegar as pessoas com maconha. Eu nem fumo mais, só que isso pouco importa, porque eles já subentendem que quem vai tomar banho de cachoeira é porque fuma um. A L. e o N. foram super-intimidados por uns policiais que ficavam insistindo: 'Cadê o flagrante?! Mostra logo!'. Eles nem estavam com nada, porque já tinham fumado e jogado a ponta fora há muito tempo".

Chegam mesmo a ser notórios os casos de consumidores de substâncias ilícitas que se envolveram em situações de suborno/extorsão, "perdendo" dinheiro ou até mesmo bens (óculos escuros, relógio etc.) para policiais, inclusive para policiais civis e policiais rodoviários federais. A maioria desses relatos refere-se ao período anterior à nova lei. No entanto, o que mudou $-\mathrm{e}$ esse é o ponto que chamamos atenção - foi o aval implícito do poder Judiciário para que esse tipo de negociação transcorra, na medida em que o processamento legal desses casos perdeu importância, mas o crime continuou existindo.

\section{O "DESENROLO"}

Durante a pesquisa de campo realizada em uma delegacia, notamos que, apesar de estar situada em um bairro de classe média rodeado por favelas onde há o varejo de drogas, não chegavam ali casos de uso e nem tão pouco de tráfico. Delegados e policiais confirmaram a nossa percepção de que esses casos não eram muito comuns naquela distrital, estando a atenção das investigações e a cobrança sobre a atuação da Polícia Militar (PM) voltadas para o combate ao roubo de carro e ao roubo a transeunte. Quando revelamos o intuito de acompanhar o registro de algum flagrante de drogas, um dos plantonistas ofereceu-se: "Se vocês quiserem eu posso ir lá fora buscar um para vocês verem".

A fala desse policial denota que eles sabem muito bem onde e como capturar e trazer para a delegacia consumidores de substâncias proibidas, no entanto, essa não é uma das suas prioridades naquela área. Conforme também assinalado em uma entrevista com um Coronel da PM, comandante de um batalhão que cobre o policiamento de uma determinada área, a 
preocupação da polícia deslocou-se, ali, da repressão ao tráfico de drogas para a prevenção dos roubos a transeunte, pois estes incidem mais fortemente sobre a sensação de insegurança das pessoas. Segundo o Coronel, a instrução para os seus subordinados é de que continuem encaminhando os casos de uso de drogas para as delegacias, mas ele não tem como controlar seus homens enquanto estão na rua e bem sabe que eles estão sujeitos a negociar os flagrantes de drogas.

Tais negociações informais fundamentam-se na apropriação particular de um bem público de monopólio estatal, isto é, o poder delegado pelo Estado ao seu agente, esperando que ele faça cumprir a lei. Dessa forma, o encaminhamento, ou não, do usuário à delegacia transforma-se em uma mercadoria política, isto é, uma mercadoria cuja produção ou reprodução depende fundamentalmente da combinação de custos e recursos políticos, para produzir um valor de troca político ou econômico (MISSE, 1999).

Contudo, não se trata apenas de uma das formas assumidas pela famosa "corrupção policial”, mas os referidos procedimentos ilegais também estão associados ao que Kant de Lima (1995) denominou por arbitragem policial, marcada pelo exercício de práticas judiciárias não oficiais. Os próprios policiais encarregam-se de punir os infratores, aplicando-lhes a pena que julgarem mais adequada, considerando a posição social do infrator e sua conduta durante o "desenrolo", como é comumente chamado o processo de negociação dos flagrantes.

M. contou que, quando era mais novo, ao ser surpreendido pela polícia enquanto fumava maconha com um amigo, em uma praça próxima à sua casa, os PMs cobraram-lhe R $\$ 2000$ para liberá-los, ao que ele retrucou: "Que isso, amigo? Assim vocês não acabam só com o meu mês não. Acabam com o ano inteiro!" Eles alegaram ser estudantes e não ter renda alguma, conseguindo reduzir o valor total para $R \$ 200$. Não se pode negar que os policiais queriam ganhar o máximo que lhes fosse possível; contudo, é necessário levar em conta que o valor extorquido - ou aceito como suborno - não representa o preço da sua honestidade. Trata-se de uma "multa" cujo preço é acordado entre as partes, de maneira que seja viável o seu pagamento, mas também cause dano ao infrator.
A punição pode passar apenas pelo prejuízo monetário conjugado à intimidação e à admoestação verbal dos indivíduos flagrados. Todavia, dependendo das circunstâncias, pode ser agravada pelo acréscimo da humilhação e da agressão física, como o "tapa na cara" ao qual alguns interlocutores aludem. A esse último tipo de punição, os usuários referem-se como "esculacho", categoria analisada por Pires (2006) e que, em seu trabalho, remete às circunstâncias em que há a ultrapassagem dos mecanismos consensuais de vigilância e repressão aos vendedores ambulantes que estudou.

Na pesquisa no Complexo do Salgueiro, notouse uma maior visibilidade da diversificação das modalidades de "penas" informais aplicadas aos usuários de substâncias ilícitas. Apesar de presente a extorsão, chamou-nos atenção a alta incidência de relatos em que tais policiais agiram com truculência, no trato com os usuários, principalmente quando se tratam de moradores de favelas, como na narrativa a seguir: "Tem um lugar que os playboys fumam lá no centro de São Gonçalo, eu também já fumei lá quando estudava lá, uma treta chamada Brejo. Do lado do valão. Só que no valão tem uma faixa enorme de terra. Tem uma casa abandonada, muito mato. Tem uma clareira, já com vários tijolos no chão. Prontinho. E ali era perto da casa de um $\mathrm{P}^{4}$. Era certo da gente rodar. Já, tipo, tomou dura. Tomou o bagulho, levou umas porradas e saiu fora. Eu uma vez ali estava com quatro amigos, fumando um dizirrê [cigarro de maconha misturado com farelos de crack]. E tinham mais ou menos umas quinze pessoas. Alguns eu conhecia de vista, outros eram amigos dos meus amigos, estavam um pouco mais afastados da gente. Bafando crack. Tava nós quatro aqui e eles um pouco mais na frente. Quando entraram dois canas. A gente teve que sair correndo porque eles já entraram aplicando. Atirando! O da frente deu dois tiros pro alto. Um deles estava uniformizado. $\mathrm{O}$ outro estava com cara de ser P2. Tava com uma camisa social e com a pochete. Você sabe, né? Aquela pochete é de lei”.

4 Policial Militar empregado no serviço reservado na corporação. Atuam sem uniforme e realizando investigações, sejam estas investigações policiais propriamente ditas, ou apurando denúncias de desvios de conduta relativas a policiais militares. 
Nos "desenrolos" entre policiais e usuários de drogas, há uma espécie de etiqueta ${ }^{5}$ que deve ser observada pelos indivíduos flagrados, prevenindose contra a possibilidade de o policial interpretar certas atitudes como falta de reconhecimento da sua autoridade, configurando um insulto moral (CARDOSO DE OLIVEIRA, 2002). Segundo os usuários, eles devem falar "de homem pra homem", porque "se fraquejar demais os homem monta" (F., usuário) e adotam-se posturas de deboche ou desrespeito, pressupondo a corruptibilidade dos agentes, podem ser "esculachados" ou até incriminados por crimes mais graves. Existe um decoro no que tange à maneira de elaborar os diálogos do "desenrolo", de modo que não se deve proferir enunciados explícitos de extorsão ou suborno, mas dissimulálos sob eufemismos como: "Pô, tá feio pro meu lado, né? Como é que se faz pra deixar isso bonito?" (M., usuário).

Quando ocorrem deslizes de conduta subjetivamente interpretados pelos policiais como desrespeito ou desconsideração, o desfecho da negociação pode ser prejudicial ao acusado. A exemplo disso, temos a história de B., que veio de Niterói ao Rio de Janeiro recolher com seus clientes o dinheiro oriundo da venda de drogas e resolveu aproveitar a viagem para ir à praia de Ipanema, encontrar os amigos no posto nove. $\mathrm{Na}$ praia, enquanto fumava um cigarro de maconha, foi surpreendido por um "P2" conhecido no local por sua severidade. Ao revistar a sua mochila, o policial encontrou a quantia de R\$1 000. B., que já assinara o antigo artigo 16 da Lei n. $6368^{6}$, restando-lhe algumas pendências, perguntou sobre como eles poderiam resolver essa situação, ao que o policial retrucou indagando: "O que você tem para me oferecer?" B. respondeu: "Você já viu o que eu tenho". E o policial ordenou: "Então pega e me mostra". Quando B. ergueu a mão para

5 Pires enfatiza a existência de um "sistema de acordos, sustentado por uma sofisticada etiqueta local" (PIRES, 2006, p. 201) que delimita os procedimentos-padrão frente aos vigilantes, permitindo a existência do comércio informal nos trens.

6 Artigo que previa o crime e as penas por uso de drogas na lei anterior à atual. Por "assinar o 16", entendia-se passar pelos procedimentos legais de incriminação por uso de drogas. mostrar-lhe o seu dinheiro, o policial deu-lhe a ordem de prisão por tentativa de suborno. B. ficou preso durante uma semana, mas conseguiu a liberdade após mobilizar a sua família e constituir um advogado.

No caso de B., havia motivos claros para que ele se preocupasse em ser levado à delegacia e buscasse recorrer ao suborno, pois além dele ser reincidente no artigo 16, o que ainda podia resultar em prisão, segundo a lei que vigorava na época, B. estava portando dinheiro demais para quem vai à praia e isso podia levantar suspeitas sobre o seu envolvimento com o tráfico de drogas. No entanto, por que é que os demais usuários também preferem submeter-se às arbitrariedades de uma negociação assimétrica e não mediada com policiais do que seguirem o curso legal do processamento dos seus casos na justiça?

\section{A TIPIFICAÇÃO CRIMINAL}

Mesmo antes da nova lei de drogas de 2006, já era raro que o acusado pelo crime de uso de drogas fosse de fato preso, tanto por conta das medidas alternativas propostas nos JECrim - a exemplo da transação penal e da suspensão condicional do processo que impedem, de certa maneira, que haja sentença condenatória de prisão - como da aplicação das penas alternativas, que possibilitam a substituição da pena privativa de liberdade pela privativa de direitos (POLICARPO, 2007). Com a mudança na lei, extinguiu-se definitivamente a possibilidade de pena de prisão para os usuários, mas ainda assim eles preferem evitar que, se flagrados, o seu caso chegue à justiça. Isso pode estar relacionado ao fato de que os usuários levados ao JECrim, continuam recebendo "informação desabonadora constante em registros de antecedentes" (ABI-EÇAB, 2007) até o cumprimento integral da medida imposta pelo juiz. Essa anotação, mesmo que temporária, traz conseqüências desagradáveis, principalmente quando se busca estabelecer vínculos de trabalho formal, como a carteira assinada (POLICARPO, 2007).

Lembremo-nos de que, apesar do fim da pena de prisão, foram mantidos os demais procedimentos criminais previstos para o tratamento legal desses casos, de modo que os acusados ainda estão sujeitos às seguintes medidas: advertência verbal, prestação de serviço à comunidade, medida educativa de comparecimento a programa 
ou curso educativo e, em último caso, multa. Como observa Karam: "Ao contrário do que muitos querem fazer crer, a Lei n. 11 343/06 não traz assim nenhuma mudança significativa nesse campo do consumo. Os 'defensores' da nova lei querem fazer crer que a previsão de penas não privativas de liberdade seria uma descriminalização da posse para uso pessoal, sustentando que somente seriam crimes condutas punidas com reclusão ou detenção (expressões utilizadas no Código Penal como espécies de prisão). Ignoram que a ameaça da pena é que caracteriza a criminalização. E penas, como a própria Constituição Federal explicita, não são apenas as privativas da liberdade, mas também as restritivas da liberdade, a perda de bens, a multa, a prestação social alternativa, as suspensões ou interdições de direitos, entre outras (KARAM, 2008, p. 116).

Ainda assim, o referido abrandamento penal a favor do usuário pode servir como argumento de negociação para os indivíduos flagrados em posse de drogas, como no caso de F.. Durante uma "dura", ele "rodou" (foi pego) com farelos de maconha no bolso e um policial cobrou-lhe R\$ 50 para liberá-lo. F. ofereceu-lhe apenas $\mathrm{R} \$ 10$, ouvindo em resposta: "Tá pensando que eu tô morrendo de fome?!", ao que F. retrucou: "Na moral, já não posso mais nem ser preso e, com isso aí, é você quem vai passar vergonha na delegacia. Só tenho R $\$ 10$ para te dar”. Os policiais ordenaram que ele ficasse parado ao lado de uma árvore e mantiveram-no por algum tempo, até que pegaram os tais R $\$ 10$ e mandaram F. embora.

Tais argumentos podem até funcionar, mas o "desenrolo" de um flagrante de drogas pode acarretar conseqüências mais graves. Como assinalou A., um policial civil: "Experimenta falar para o PM que 'ah, isso é pouquinho... não vai dar nada' pra você ver. Ele vai na viatura e arruma mais um quilo pra botar na tua conta". Exageros à parte, é realmente usual que os flagrantes conduzidos à delegacia ganhem um peso a mais, como no caso narrado por Veríssimo (2008) em que o "autor do fato" reconheceu estar portando maconha, mas indignou-se ao perceber que haviam acrescentado bastante à quantidade apreendida, ainda que isso não tenha mudado nada no registro da ocorrência.

Deparamo-nos agora com o ponto mais crítico do "desenrolo": a mercadoria política em jogo não é apenas o registro ou não do flagrante, mas também o tipo criminal em que a situação de porte ilegal de drogas vai ser classificada, se uso ou tráfico. Quando esses flagrantes chegam à delegacia, são os delegados e policiais civis de plantão que fazem a tipificação criminal, com base, porém, na descrição oferecida pelo "condutor", normalmente um policial militar. As suas declarações orientam a formulação da "dinâmica do fato" e, se enquadrado como usuário, o acusado deverá apenas assinar o Termo Circunstanciado, sendo logo liberado, ao passo que, se configurar um caso de tráfico, inicia-se a lavratura de um Auto de Prisão em Flagrante e o acusado vai para a prisão, onde aguardará pelo julgamento.

Acrescentemos ainda que a Lei n. 11 343/06, em contrapartida ao abrandamento penal em face ao uso de drogas, endureceu a punição para o crime de tráfico, aumentando a pena mínima de três para cinco anos de reclusão. Boiteux sugere que uma das conseqüências desse rigor penal sobre o tráfico poderá ser o aumento da população carcerária, na medida em que os traficantes permanecerão mais tempo na prisão, "além de ter sido mantida, pelo art. 44 da nova lei, a inafiançabilidade do delito, proibida a concessão de sursis, graça, indulto, anistia e liberdade provisória, bem como a conversão da pena em restritiva de direitos, o que fará com que os presos por tráfico fiquem encarcerados um tempo ainda maior" (BOITEUX, 2006, p. 4).

Além disso, ao examinar as sentenças e acórdãos relacionados ao tráfico de drogas, a mesma autora sugere que, apesar do parágrafo $4^{\circ}$ do artigo $33^{7}$ que trata do tema possibilitar "uma causa especial de redução da pena em determinadas hipóteses, quando a conduta é considerada menos grave" (idem, p. 35) os juízes insistem, mesmo com os acusados preenchendo todos os requisitos, em considerar os réus como fazendo parte do "crime organizado".

Tendo em vista as considerações apresentadas sobre os processos do "desenrolo" dos flagrantes, outra provável conseqüência dessa bifurcação no

7 Parágrafo $4^{\circ}$, do artigo 33 da Lei n. 11 343/06: "nos delitos definidos no caput e no $\S 1^{\circ}$ deste artigo, as penas poderão ser reduzidas de $1 / 6$ a $2 / 3$, vedada a conversão em penas restritivas de direitos, desde que o agente seja primário, de bons antecedentes, não se dedique às atividades criminosas e nem integre organização criminosa". 
tratamento penal é o aumento da margem de barganha sobre o tipo penal em que serão classificados os flagrantes de drogas - tráfico ou uso - uma vez que a lei não estabelece critérios objetivos para distinguir entre os dois, apesar de determinar penas tão discrepantes. Ao examinar dados policiais, Alba Zaluar já observara, desde antes da nova lei, que a indefinição entre usuário e traficante favorece a inflação do poder policial: "A quantidade apreendida não é o critério diferenciador, pois encontram-se casos classificados como 'posse e uso' com 1860 gramas de maconha apreendida e casos classificados como 'tráfico' com apenas 2 gramas. Essa indefinição, que está na legislação, mas principalmente na prática policial, só vai favorecer a inflação do poder policial, o que, por sua vez, vai inflacionar a corrupção" (ZALUAR, 1999, p. 113).

Um entrevistado do Complexo do Salgueiro comentou sobre como o ato da própria tipificação penal que diferenciará usuários de traficantes para além das idiossincrasias dos policiais transita por fronteiras, na prática, igualmente confusas. "Na minha visão, usuário não é bandido. Mas na opinião dos canas... E é uma linha também muito fina, principalmente na favela. Quem usa acaba vendendo. Tipo, eu não me vejo trabalhando na boca. Eu comprava a maconha de $\mathrm{R} \$ 2$, e vendia cada uma delas por R \$ 5 [na escola onde estudava, para colegas que não entravam na favela para comprar a droga]. Eu tirava o carimbo delas. É lei da favela tirar o carimbo. Eu não posso vender maconha com o carimbo da favela. Porque carimbo é uma coisa da boca. E eu não sou da boca. Nunca fui. Mas fiquei dois meses fazendo isso. Por isso que eu falo que essa linha é uma linha fina, tênue. Viciado faz isso toda hora. Pra poder se sustentar e ter o dele. Tira um dinheiro da carteira do pai, vai na Mineira [Morro da Mineira, no centro da cidade do Rio de Janeiro], compra um pó de 50 e vende aqui [em São Gonçalo]. Tipo, oito de R\$ 10. Porque o de lá é muito maior do que o daqui. Um de dez de lá são dois daqui. Eu não ficava sem dinheiro. Eu não tinha um lucro imenso, mas não ficava sem dinheiro. E tinha pro meu consumo. Era só pra curtir. E na favela essa linha é menor ainda".

Em conversa com um policial militar, este indicou como é a estratégia para aumentar o poder de barganha durante a negociação do flagrante. Segundo o entrevistado, quando o policial quer "ganhar uma grana maior" do usuário flagrado, o detido é "instigado" a agir de maneira que o incrimine, como gritar com o policial ou responder a provocações, podendo ser preso por desacato e resistência à prisão e, em situações mais sérias, o policial pode provocar uma "confissão" de tráfico: "É forçar o cara a dizer que tá levando a droga pra alguém: 'Você aí com dois papelotes, tava levando pra alguém. Pra quem? Não é só seu não, é melhor falar!'. Força, força, até o cara falar: '... É, tava levando pra usar com minha namorada...'. Pronto! Aí os policiais falam: 'Tá preso, vambora. Você confessou. Isso é tráfico"”.

Trata-se, pois, de uma forma de construção da verdade em que o uso da violência e da extorsão adquire formas complexas, utilizando-se de expedientes diversificados e tendo por objetivo variados fins. A categoria "terror psicológico" foi utilizada por todos os interlocutores do Complexo do Salgueiro. Vejamos abaixo o relato de um deles que, retido na época por policiais militares, a despeito de efetivamente trabalhar para o tráfico local, não portava nada que o pudesse comprometer naquela ocasião específica. "Eu não estava com nada. Eles queriam me forjar, aí eu falei, não é meu, não é meu, não é meu... Eles começaram a me chamar pelo nome de um outro bandido, que na época, tava vivo, e eu dizendo que não era eu, não era eu... Sendo que eles já sabiam quem era eu. Eles queriam, tá ligado, tipo assim, terror psicológico, pra eu dar um dinheiro e pum... Não me pegaram com nada, então eles queriam me forjar, falaram que iam me matar, rodaram comigo a favela todinha... Estavam me levando pra Guaxindiba [bairro quase rural, no limite entre os municípios de São Gonçalo e Itaboraí]. Não me ficharam, mas tiraram as minhas digitais, não me botaram pra assinar nada. Eles queriam me botar uma carga de maconha e um oitão. E eu não meti a mão em nada, porque senão eles iam pegar minhas digitais. Aí, como eu me segurei... Fizeram um terror psicológico, fiquei lá só algumas horas. Cheguei lá de manhã, saí só de noite".

Como estamos vendo, ao abismo entre as penas para uso e tráfico de drogas soma-se a imprecisão dos critérios para distinguir entre esses crimes, podendo favorecer práticas de extorsão. Eis como a Lei n. 11 343/06 define o que 
constituem estes delitos: "Usuário: Art. 28. Quem adquirir, guardar, tiver em depósito, transportar ou trouxer consigo, para consumo pessoal, drogas sem autorização ou em desacordo com determinação legal ou regulamentar.

Traficante: Art. 33. Importar, exportar, remeter, preparar, produzir, fabricar, adquirir, vender, expor à venda, oferecer, ter em depósito, transportar, trazer consigo, guardar, prescrever, ministrar, entregar a consumo ou fornecer drogas, ainda que gratuitamente, sem autorização ou em desacordo com determinação legal ou regulamentar".

Os parâmetros para a realização da tipificação criminal encontram-se no parágrafo $2^{\circ}$ do artigo 28 desta mesma lei: “Artigo 28, § $2^{\circ}$ : Para determinar se a droga destinava-se a consumo pessoal, o juiz atenderá à natureza e à quantidade da substância apreendida, ao local e às condições em que se desenvolveu a ação, às circunstâncias sociais e pessoais, bem como à conduta e aos antecedentes do agente".

A mesma situação de porte ilegal de drogas pode ser apresentada como artigo 28 ou 33, dependendo da interpretação sobre a intenção por trás da posse da substância. A subjetividade dos critérios abre espaço para a reificação das préconcepções policiais sobre quem sejam os traficantes e os usuários. Os critérios enunciados por alguns policiais civis, durante a pesquisa de campo em uma delegacia, revelam alguns aspectos da seletividade policial: "Se um cara é pego com drogas, mesmo que em pequena quantidade, e estiver em um lugar onde todo mundo sabe que tem uma boca, se ele morar naquela comunidade, ele pega tráfico. Se o cara for lá de Duque de Caxias, mesmo que esteja com uma quantidade maior, vai pegar uso, pois a gente sabe que ele não tava vendendo ali. Mas aí a gente pede a carteira de trabalho. Se ele tiver emprego, tudo bem, mas se não tiver emprego, tava comprando droga com que dinheiro? Era pra revender, né? Aí ele pega tráfico" (A., policial civil).

Tanto os procedimentos de vigilância quanto os de incriminação dos suspeitos recaem sobre indivíduos já identificados na malha policial ou sobre aqueles que se enquadram nos tipos sociais potencialmente criminosos, criminalizando-os preventivamente. Trata-se da sujeição criminal, "processo social que incide sobre a identidade pública, e muitas vezes íntima, dos indivíduos" (MISSE, 1999, p. 210), que subjetivam os rótulos a eles atribuídos.

Kant de Lima observou que "[...] os critérios para avaliar a eficiência da polícia (p. ex., o número de prisões) tendiam a depender dos estereótipos policiais de crimes e criminosos - e reproduzi-los. Conseqüentemente, muito mais do que 'reconstituição' dos fatos eles eram procedimentos de 'reconhecimento"" (KANT DE LIMA, 1995, p. 78).

O tipo penal a ser aplicado é definido também a partir de negociações discursivas sobre a versão do fato que é apresentada na delegacia e a que vai para os "autos". J., policial civil, contou-nos a história de um rapaz flagrado no interior de um táxi com três papéis de cocaína. Segundo J., os PMs tinham tentado "desenrolar um dinheiro com o cara", mas o rapaz não aceitou, dizendo que trabalhava no prédio da corregedoria deles e que a droga era para o seu patrão. Os PMs levaramno para a delegacia, relatando que ele fornecera uma confissão de tráfico. Ao saber que o acusado era um morador da favela que, aos seus 22 anos, trabalhava, cursava o ensino superior e não possuía antecedentes criminais, J. tentou dissuadir os policiais militares de apresentarem tal versão, mas não obteve sucesso. Ele insistiu com a delegada assistente, mas após conversar com os $\mathrm{PMs}$, ela confirmou que o caso era de tráfico. J. continuou tentando: "Fui falar em particular com o cara e disse: 'Meu irmão, a doutora vai entrar aqui e você vai falar para ela que essa cocaína era toda sua e que você ia cheirar essa porra toda sozinho! Valeu?'

Mas não deu outra. A doutora entrou na sala e perguntou: 'Essa droga é sua?' E ele: 'Não. Era para o meu patrão'. Então toma dois anos de cadeia nas costas, vai! Mas também, eu fui e botei tudo no flagrante: 'os policiais cobraram dinheiro...'. Fode o cara, mas também vai se foder respondendo depois. Um cara desse, que andava na linha direitinho, vai sair da cadeia cheio de ódio de polícia, já pegando no fuzil".

É a narrativa do "condutor" que fornece os elementos para encaixar o fato em um artigo do código penal. Os policiais civis costumam dizer que acatam rigorosamente as declarações do policial militar, tipificando os casos de acordo com a sua descrição. No entanto, já foi possível obser- 
var um caso em que o delegado convenceu o policial militar a modificar as suas declarações para que um caso de desacato à autoridade não se transformasse em uma lavratura de flagrante por tentativa de suborno, cuja elaboração tomaria mais tempo do policial civil de plantão, ou como nas suas próprias palavras: “Assim não dá! Assim vai quebrar o plantão! Isso acaba com o plantão! Eu tenho problema de pressão! Posso morrer a qualquer momento! Só tem dois policiais de plantão o dia inteiro e ele me vem com isso a essa hora!!! Se deixar, a gente vai ficar aqui até depois da hora! Vamos ficar aqui até as $8 \mathrm{~h}$ da manhã!" (C., policial civil).

Os registros realizados nas delegacias são peças determinantes na instrução da fase judicial do processamento dos crimes e precisam apresentar informações e provas consistentes para que a ação penal seja levada adiante e para que venha a subsidiar o chamado "livre convencimento do juiz". Portanto, é de suma importância que os Autos de Flagrante sejam bem redigidos e que não produzam contradições passíveis de fazer configurar uma prisão ilegal. O poder de levar um indivíduo ao cárcere concentra-se nas mãos de policiais e delegados, quando se trata de um flagrante, uma vez que uma narrativa coerente da "dinâmica do fato" é o que constitui o fato criminal. Contudo, "[...] a polícia barganha, negocia, oficiosa e/ou ilegalmente, em troca de algum tipo de vantagem, tanto o que investiga, como o que os escrivães policiais escrevem nos 'autos' do inquérito policial, o que se denomina, mesmo, por uma categoria específica: a 'armação do processo"” (KANT DE LIMA, 2007, p. 179).

$\mathrm{O}$ juiz deve ser imediatamente informado da prisão de um indivíduo, mas o prazo até que o processo físico (os papéis) do Auto de Prisão em Flagrante chegue às suas mãos é de dez dias. Esse é um período em que o conteúdo dos documentos ainda pode ser modificado. Levemos em consideração que a fase policial do processamento dos crimes é marcada pela ausência do contraditório, existente apenas no caso do acusado instituir um advogado particular que desfrute de prestígio e/ou conhecimentos na polícia.

A construção da narrativa dos fatos é mediada por todas as referidas disputas e negociações e remete ao processo da criminação-incriminação, definido pelo enquadramento de um curso de ação na classificação criminalizadora típico-idealmente definida, isto é, a criminação de um evento, e a atribuição do fato criminal a um suposto sujeitoautor, enfim, a sua incriminação (MISSE, 1999). A elaboração do texto oficial final, que descreve as circunstâncias do flagrante, vai encaixar um indivíduo nas categorias de usuário ou traficante que, apesar da imprecisão nos parâmetros que as separam, possuem previsões de pena tão díspares.

Em contraste com a diminuição dos registros de uso de drogas, após entrar em vigor a nova lei, os casos registrados como tráfico aumentaram, conforme o gráfico abaixo.

A comparação entre as somas dos 24 meses anteriores e os posteriores à entrada em vigor da

GRÁFICO 2 - TRÁFICO DE DROGAS NO ESTADO DO RIO DE JANEIRO (2003-2008)

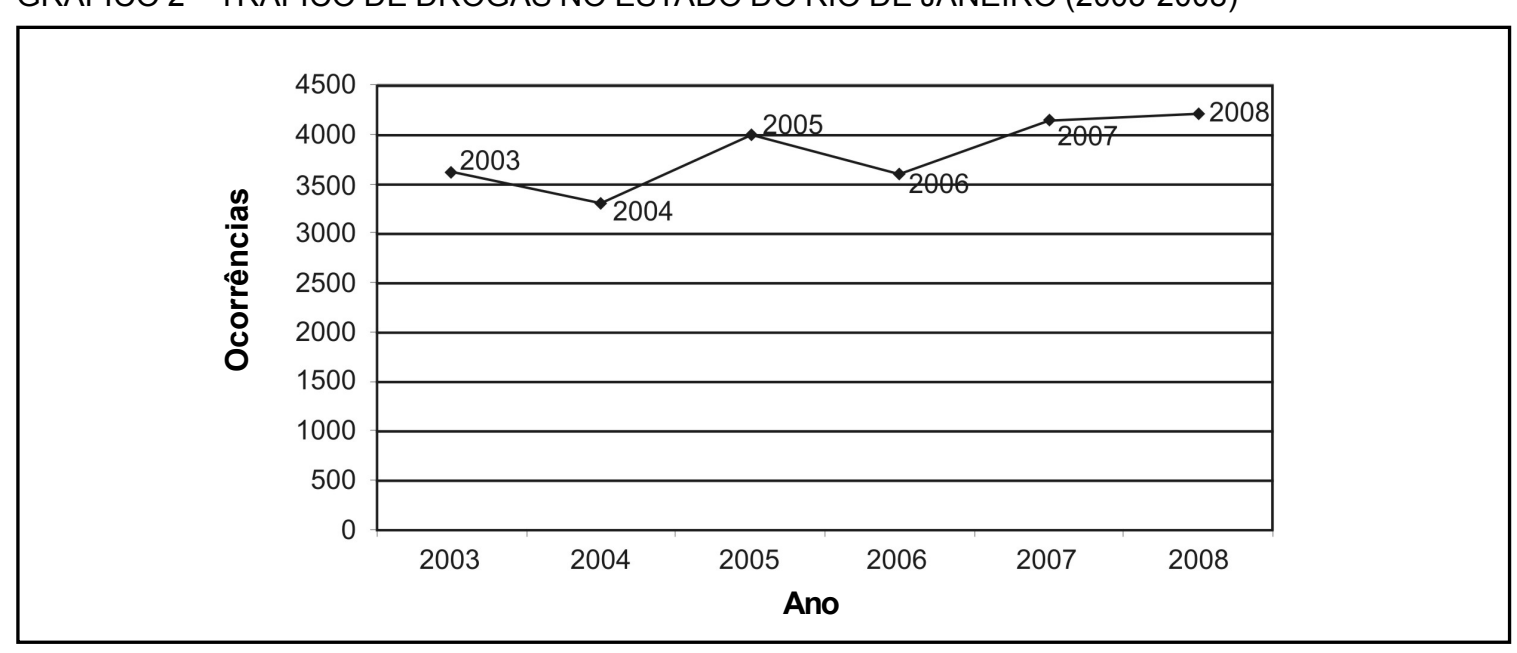

FONTE: ISP-RJ (2011). 
nova lei de drogas revelou que os totais de incidência para tráfico cresceram $8,2 \%$. Será que parte dos flagrantes antes registrados como uso não estaria entrando como tráfico? Essa hipótese não é possível de ser verificada, devido à obscuridade dos critérios da tipificação, mas representa uma das explicações plausíveis para as variações encontradas nos dados sobre entorpecentes.

\section{TRAFICANTE OU USUÁRIO?}

A ausência de critérios que facilitem a distinção entre o uso e o tráfico não é uma imperfeição da lei, mas uma conseqüência da impossibilidade de uma diferenciação objetiva e eficaz. As classificações penais são arbitrárias e fundamentam-se em representações das ações criminosas, formulando generalizações incapazes de abarcar a complexidade encontrada no mundo, como tivemos a oportunidade de ver por meio dos relatos transcritos acima. Algumas personagens parecem borrar por completo as fronteiras construídas pela lei entre os traficantes e usuários.

Não raro, em redes sociais de traficantes de classe média do Rio de Janeiro, observa-se que, apesar de venderem drogas ilícitas, interlocutores não se percebiam como traficantes e não havia, na trajetória dos mesmos, um marco relativo à passagem de consumidor a comerciante (GRILLO, 2008). Eles procuravam vender drogas apenas entre amigos e conhecidos, manipulando a contradição entre a necessidade de encobrir as suas práticas ilícitas, restringindo a rede de indivíduos com os quais se relacionavam comercialmente e a vantagem de expandir essas redes, lucrando com a diversificação de contatos para compra e venda de mercadorias. Dessa maneira, caso um cliente queira "adiantar" (ajudar) amigos que não tenham "contato" para a aquisição de drogas, ele deverá comprar em maior quantidade e repassar aos amigos, pois ele não pode simplesmente apresentá-los ao seu "contato". Um consumidor, então, pratica o tráfico de drogas apesar de não ser essa a sua intenção e, se passar a lucrar sobre a droga que faz circular, pode até profissionalizar-se, incorporando tal prática ao seu cotidiano. É assim que os traficantes de classe média começam as suas carreiras e que as redes desse mercado ramificam-se.
Barbosa (1998) também chama a atenção para a dificuldade em efetuar a distinção entre traficantes e usuários de drogas, considerando as práticas de uso, circulação e comércio das drogas no Rio de Janeiro e os valores associados a esse universo. O autor aponta uma figura emblemática dessa fronteira indistinta entre a drogadição e o tráfico entre o consumo e o ganho - e os riscos associados à venda de drogas. Trata-se de uma personagem facilmente encontrada nas ruas, nas diversas regiões da cidade, e que as gírias denominam por "avião": aquele encarregado de "subir o morro" ou entrar na favela para buscar a droga, recebendo, em contrapartida, uma parte em dinheiro ou em drogas para o seu próprio consumo.

Tais apontamentos aparecem mais claramente no seguinte caso: T. P. e G., três moças de "classe média alta" $"$, foram assistir a um espetáculo em uma casa de eventos situada no bairro da Lapa. Elas estavam ansiosas para consumir cocaína juntas, mas já era muito tarde para ligar para os "contatos" que possuíam com traficantes de classe média, o que seria interpretado como inconveniente. T. e P. também costumavam comprar cocaína próximo ao shopping center onde fazem compras, cooptando guardadores de carro para que eles "fizessem o avião" para elas. Como P. passara a estacionar por lá todos os dias, devido ao seu novo trabalho, não seria adequado que ela continuasse a expor-se naquele local. Sem saber como conseguir a droga, G. sugeriu que elas abordassem na rua alguém que aparentasse estar "pancado" (sob efeito da cocaína), solicitando-lhe que as colocassem no seu "contato" - afinal, "não é possível que em plena Lapa não exista ninguém vendendo pó". T. concordou de imediato, mas P. indignou-se com a proposta.

Ao serem interpeladas por um cambista que tentava vender-lhes ingressos para o show que elas assistiriam, G. e T. entreolharam-se e comentaram: "É esse!", vendo que ele estava com o maxilar travado e o queixo tremendo, $\mathrm{T}$. perguntou: "Moço, você sabe onde é que a gente pode arrumar um do branco?". Um tanto surpreso, ele respondeu que sim e convidou-as a segui-

8 Tomamos "classe média alta" como categoria nativa. As referidas moças possuíam nível superior completo e eram oriundas de famílias com uma confortável situação financeira. 
lo. P. não as acompanhou. As duas foram levadas até uma rua onde, após fornecer ao cambista o valor de seis sacos de $\mathrm{R} \$ 10$, aguardaram que ele fosse até os vendedores da droga. Quando o cambista voltou, consumiu parte da droga junto com as duas, até que voltaram para perto da casa de eventos. Ele vendeu-lhes um ingresso a preço de custo e elas reencontraram P., com quem repartiram o restante da cocaína.

Quem é traficante e quem é usuário nessa história? As jovens transformam usuários em traficantes, quando os "seduzem" a conseguir drogas para elas. No entanto, elas mesmas engajam-se em cursos de ação classificáveis como tráfico, ao fornecer a substância ilegal para uma amiga. Talvez, os únicos que se percebam como traficantes nesse caso sejam os que ficam parados na rua e, ainda assim, eles também devem ser usuários. Conforme assinalado por William $\mathrm{S}$. Burroughs, baseando-se na sua experiência com opiáceos: "Nunca vi um viciado que não vendesse, nem um traficante que não fosse viciado" (BURROUGHS, 2005, p. 250).

Os dados coletados indicam haver, entre os usuários, gradientes variáveis de envolvimento com a circulação das drogas, partindo desde o consumidor que não compra nem a parte que consome, usando apenas o que lhe é oferecido gratuitamente pelos outros, até o consumidor que, além de sustentar o seu próprio consumo com a venda dessas mercadorias, tem essa atividade comercial como a sua única fonte de renda. Entre esses opostos, é possível encontrar diversas nuances intermediárias, como o usuário que às vezes vende drogas para pagar apenas o seu consumo, ou aquele que doa uma pequena quantidade a um amigo que esteja sem nada.

A nova lei avançou no sentido de considerar alguns aspectos sobre os contextos empíricos de consumo, ao introduzir um atenuante no parágrafo $3^{\circ}$ do artigo 33 , reduzindo a pena para seis meses a um ano, se o crime cometido for "oferecer, eventualmente e sem objetivo de lucro, a pessoa de seu relacionamento, para juntos a consumirem". Apesar desses casos permanecerem classificados como tráfico, foi minimamente levado em conta o fato de que os usuários, na maioria das vezes, consomem drogas em companhia de outros, com os quais a compartilham.
No mais, a legislação brasileira ignora essa complexidade, estabelecendo as bases formais para que a elaboração retórica sobre um contexto de flagrante possa sintetizar uma existência individual em uma identidade criminosa que lhe é atribuída. Segundo Turk (1966), o status de um indivíduo não é avaliado pelo que ele é ou faz, mas por meio da reação dos outros que o percebem, utilizando algum de seus atributos ou um aspecto do seu comportamento como critério. Para o autor, o processo acusatorial da criminalização, definido pela atribuição de um rótulo por parte das autoridades legais, é a origem da criminalidade do indivíduo.

\section{CONCLUSÕES}

Assistimos a um momento em que as políticas públicas desenvolvidas no Brasil para tratar dos problemas relacionados às drogas vêm alinhandose com as tendências internacionais, de maneira a assumir o caráter de uma economia repressiva dual (CUNHA, 2002), isto é, como já foi colocado, estabelecendo penas cada vez mais brandas para o usuário e mais duras para o traficante. A nova lei de drogas consolidou essa postura, que representa uma nova fase nas políticas de repressão às drogas.

Após a detenção de três indivíduos que fumavam maconha na praia de Ipanema, algumas autoridades pronunciaram-se no intuito de reforçar a distinção legal entre os traficantes e usuários. "Os ministros da Secretaria Especial de Direitos Humanos, Paulo Vanucchi, e do meio ambiente, Carlos Minc, negociam dentro do governo uma proposta para ampliar o alcance da nova lei de entorpecentes. A legislação em vigor já exclui a pena de prisão para usuários de drogas, mas Minc e Vanuchi entendem que seria importante estabelecer regras ainda mais claras para assegurar tratamento diferenciado aos consumidores. Para Minc, brechas nas regras deixam usuários expostos a constrangimento, corrupção e extorsão por parte de autoridades encarregadas de combater o tráfico" (MINISTROS ESTUDAM MUDANÇAS, 2009).

A proliferação de discursos políticos similares - a exemplo do documento final da Comissão Latino-Americana Sobre Drogas e Cidadania partem de representações construídas ao longo de décadas de guerra às drogas. "As sociedades modernas escolheram a repressão legal como 
instrumento de regulação de custos externos atribuídos a opções morais de usuários e estratégias empresariais dos traficantes" (PAIXÃO, 1994, p. 129). Uma das conseqüências dessa política pública de "guerra contra as drogas" é que ela "origina e 'alimenta' um mercado, que 'produz' o criminoso e as suas variantes, e fornece as fontes para a construção das representações sociais do mal" (DOS SANTOS, 2004, p. 37). A figura do traficante tem sido o bode expiatório para todos os males resultantes do fracasso das políticas antidrogas, servindo como fundamento para a intensificação dos investimentos no mesmo modelo repressivo.

O "problema das drogas" vem complicandose de tal forma que a opinião pública parece concordar que sua "solução" deva passar pela vigente suspensão dos direitos civis de uma série de indivíduos, fundamentando-se no bem maior almejado, que é o combate às substâncias proibidas (idem). De modo particular, essas violações dos direitos civis apresentam-se, no Brasil, com feições ainda mais contundentes, pois o valor da igualdade, apesar de permear os repertórios discursivos da esfera pública, não se realiza no espaço público propriamente dito (CARDOSO DE OLIVEIRA, 2002). Conforme assinalado por Kant de Lima (1995) sobre o paradoxo legal brasileiro, as regras constitucionais que estabelecem a igualdade jurídica entre as pessoas - a proposição de que todos são iguais perante a lei - coexistem com regras processuais que instituem a desigualdade jurídica de maneira explícita - como no caso da prisão especial, do foro privilegiado etc. Esse sistema judicial hierárquico está associado às práticas policiais arbitrárias e repressivas que recaem de maneira ainda mais incisiva sobre as populações pauperizadas, rotineiramente sujeitas à suspeição e às averiguações policiais.

Os dados desta pesquisa sugerem que a atual legislação sobre drogas favoreceu tais práticas policiais arbitrárias e a transformação dos registros de ocorrência em mercadorias políticas, havendo uma diminuição do processamento legal dos casos de uso. Ocasião esta em que supostamente haveria a presunção de inocência, o direito à defesa, e demais ponderações ao exercício do poder punitivo do Estado. Ainda que os direitos não se realizem na prática, como nas audiências do JECrim realizadas sem defensor público e nem promotor, observadas por Policarpo (2007), e embora a lei brasileira institua a desigualdade entre os cidadãos, ela estabelece alguns limites na relação formalmente assimétrica entre o sistema de justiça criminal e seus acusados.

O "desenrolo", informalmente sancionado, constitui-se por meio de uma interação assimétrica, legalmente irregulada, isto é, controlada apenas pelos eventuais policiais. A referência ao Estado dilui-se nos ilegalismos (FOUCAULT, 1984), de modo que ele só se faz presente no poder delegado ao seu agente, que é, muitas vezes, apropriado particularmente. Assim, embora a lei aponte para a descriminalização do uso, pois abranda as medidas contra o usuário, é necessária atenção para a atual situação da repressão às drogas e ao tratamento dispensado pelos operadores da justiça criminal com relação aos usuários, para que as mudanças na direção da garantia dos direitos individuais não tenham o efeito contrário do esperado. Isto é, em vez de caminharmos para a consolidação da idéia dos usuários de drogas como sujeitos de direitos, como quer Garapon (2004), aptos, como qualquer cidadão, a participar das decisões que os atingem, talvez estejamos seguindo na direção contrária, incrementando práticas ilegais discricionárias e abusivas que nos distanciam dos valores do Estado democrático de direito e da cidadania (MARSHALL, 1967) $^{9}$.

Soma-se a isso, ainda, o fato inegável de que a naturalização da desigualdade dos cidadãos perante os mecanismos jurídicos e coercitivos "é um dos princípios organizadores da sociedade brasileira" (KANT DE LIMA, 2008). Em uma situação como essa, jovens moradores de favelas acabam sendo levados a corresponderem, em suas respectivas biografias, com estereótipos criminalizadores. Ou, como disse um desses jovens entrevistados no Complexo do Salgueiro: "Tem gente aí que nunca saiu, nunca foi num cinema, nunca foi ao McDonald's. Não vai ao centro de São Gonçalo. Só sabe andar em favela. Nunca saiu. Sai daqui pra ir a outra favela e volta. Entendeu? Se você largar ele no meio do Rio, ele não sabe voltar. Então, o que é que é a mentalidade dele? Favela! Ainda mais se, tipo, se ele for pobre, é pior. Eu conheci gente da $4^{\mathrm{a}}$ série no Brizolão

9 Para uma discussão sobre a noção de cidadania no Brasil, tendo como referência o texto citado de Marshall, ver Kant de Lima (2004) e Teixeira Mendes (2005). 
que não sabia ler. Então, um garoto de 15 anos que está na quarta série e não sabe ler, qual é a perspectiva dele pra vida? Me fala aí! Boca! Tráfico! Ainda mais se ele não tiver uma família maneira".
A ação dos mecanismos de coerção do Estado, amparados nas indefinições de leis como a da nova lei de drogas - a despeito de seu caráter apenas aparentemente liberalizante -, contribui para consolidar a efetividade de estereótipos já arraigados.

Carolina Christoph Grillo (carolina.grillo@yahoo.com.br) é Doutoranda em Sociologia e Antropologia na Universidade Federal do Rio de Janeiro (UFRJ).

Frederico Policarpo (fredericopolicarpo@yahoo.com.br) é Doutorando em Antropologia da Universidade Federal Fluminense (UFF).

Marcos Veríssimo (marcusverissimus@yahoo.com.br) é Doutorando do Programa de Pós-Graduação em Antropologia da Universidade Federal Fluminense (UFF).

\section{REFERÊNCIAS BIBLIOGRÁFICAS}

BARBOSA, A. R. 1998. Um abraço para todos os amigos: algumas considerações sobre o tráfico de drogas no Rio de Janeiro. Niterói: UFF.

BOITEUX, L. 2009. Tráfico de drogas e Constituição. Resumo do Projeto de Pesquisa apresentado ao Ministério da Justiça/PNUD, no Projeto "Pensando o Direito", referência Prodoc BRA/08/001. Disponível em: http:// arquivos.informe.jor.br/clientes/justica/ agencia/agosto/Sumario_executivo_pesquisa Trafico.pdf. Acesso em: 5.set.2011.

2006. A Nova Lei Antidrogas e o aumento da pena do delito de tráfico de entorpecentes. Boletim do Instituto Brasileiro de Ciências Criminais, São Paulo, ano 14, n. 167, Out. Disponível em: http://www.neip.info/ downloads/luciana/artigo_drogas_Luciana Boiteux.pdf. Acesso em: 5.set.2011.

BURROUGHS, W. S. 2005. Junky. Rio de Janeiro: Ediouro.

CARDOSO DE LIVEIRA, L. R. 2002. Direito legal e insulto moral: dilemas da cidadania no Brasil, Quebec e EUA. Rio de Janeiro: Relume Dumará.

CUNHA, M. I. 2002. Entre o bairro e a prisão: tráficos e trajetos. Lisboa: Fim de Século.

DOS SANTOS, D. 2004. Drogas, Globalização e Direitos Humanos. Antropolitica, n. 16, Niterói, p. 21-53, $1^{\circ}$ sem. Disponível em: http:/ /www.adelinotorres.com/sociologia/ Daniel_dos_Santos_DROGAS\%20E\%20 DIREITOS \%20HUMANOS.doc. Acesso em: 5.set.2011.

ABI-EÇAB, P. 2007. Questões processuais da Nova Lei de Drogas. Consultor Jurídico, 30.mar. Disponível em: http://www.conjur. com.br/2007-mar-30/questoes_processuais_ lei_toxicos. Acesso em: 5.set.2011.

FOUCAULT, M. 1984. Vigiar e punir: nascimento da prisão. Petrópolis: Vozes.

GARAPON, A. 2004 El toxicomano y la justicia: ¿Como restaurar el sujeto de derecho? In: EHRENBERG, A. Individuos bajo influencia: drogas, alcoholes, medicamentos psicotrópicos. Buenos Aires: Nueva Visión.

GRILLO, C. C. 2008. Fazendo o doze na pista: um estudo de caso do mercado ilegal de drogas na classe média. Rio de Janeiro. Dissertação (Mestrado em Antropologia). Universidade Federal do Rio de Janeiro.

IDP-RJ. 2011. Dados oficiais. Rio de Janeiro: Instituto de Segurança Pública. Disponível em : http://www.isp.rj.gov.br. Acesso em 5.set.2011.

KANT DE LIMA, R. 1995. A polícia da cidade do Rio de Janeiro: seus dilemas e paradoxos. Rio de Janeiro: Forense.

2007. Direitos Civis e Direitos Humanos no Brasil: uma tradição judiciária pré- 
republicana? In: KANT DE LIMA, R. Ensaios de Antropologia e de Direito: acesso à justiça e processos institucionais de administração de conflitos e produção da verdade jurídica em uma perspectiva comparada. Rio de Janeiro: Lumen Juris.

KARAM, M. L. 2008. A Lei 11 343/06 e os repetidos danos do proibicionismo. In: LABATE, B. C.; GOULART, S. L.; FIORE, M.; MACRAE, E. \& CARNEIRO, H. (orgs.). Drogas e cultura: novas perspectivas. Salvador: UFBA.

MARSHALL, T. H. 1967. Cidadania, classe social e status. Rio de Janeiro: J. Zahar.

MISSE, M. 1999. Malandros, marginais e vagabundos \& a acumulação social da violência no Rio de Janeiro. Rio de Janeiro. Tese (Doutorado em Sociologia). Instituto Universitário de Pesquisas do Rio de Janeiro. Disponível em: http://necvu.tempsite.ws/ images/tese\%20michel.pdf. Acesso em: 5.set.2011

2003. O movimento: a constituição e reprodução das redes do mercado informal ilegal de drogas a varejo no Rio de Janeiro e seus efeitos de violência. In: BAPTISTA, M.; CRUZ, M. S. \& MATIAS, R. (orgs.). Drogas e pós-modernidade. V. 2. Rio de Janeiro: UERJ.

PAIXÃO, A. L. 1994. Problemas sociais, políticas públicas: o caso dos tóxicos. In: ZALUAR, A. (org.). Drogas e cidadania. São Paulo: Brasiliense.
PIRES, L. 2006. "Deus ajuda a quem cedo madruga?": trabalho, informalidade e direitos civis nos trens da Central do Brasil. In: MACHADO, L.; HEILBORN, M. \& GROSSI, M. P. (orgs.). Antropologia e direitos humanos. V. 4. Blumenau: Nova Letra.

POLICARPO, F. 2007. O programa Justiça Terapêutica da Vara de Execuções Penais do Rio de Janeiro. Rio de Janeiro. Dissertação (Mestrado em Antropologia). Universidade Federal Fluminense.

TEIXEIRA MENDES, R. L. 2005. Igualdade à brasileira: cidadania como Instituto Jurídico no Brasil. In: KANT DE LIMA, R.; MENDES, R. L. T. \& AMORIM, M. S. (orgs.). Ensaios sobre a igualdade jurídica. Rio de Janeiro: Lumen Juris.

TURK, A. T. 1996. Conflict and Criminality. American Sociological Review, Washington (DC), v. 31, n. 3, p. 338-352, June.

VERÍSSIMO, M. 2008. A Lei e a Moral: Apontamentos para o estudo da lógica jurídico-policial no Brasil. Trabalho apresentado nas $5^{\text {a }}$ Jornadas de Investigación en Antropología Social, Buenos Aires. Digit.

2009. O crack e os impactos de sua entrada em uma comunidade da Região Metropolitana do Rio de Janeiro. Trabalho apresentado na $8^{a}$ Reunión de Antropología Del Mercosur, Buenos Aires. Digit.

ZALUAR, A. (org.). 1999. Drogas e cidadania: repressão ou redução de riscos. São Paulo: Brasiliense.

\section{OUTRAS FONTES}

Ministros estudam mudanças na lei para proteger usuários de drogas. 2009. O Globo, 5.fev. Disponível em: http://oglobo.globo.com/rio/ mat/2009/02/04/ministros-estudam- mudancas-na-lei-para-proteger-usuarios-dedrogas-754266682.asp. Acesso em: 5.set.2011. 
THE "HARD LINE" AND "GETTING OFF THE HOOK": PRACTICAL EFFECTS OF THE NEW DRUG LAW IN RIO DE JANEIRO

Carolina Christoph Grillo, Frederico Policarpo and Marcos Veríssimo

This article analyzes the effects of the new drug law on legal repression of drug use and formal trial of cases that appear before the criminal justice system. We seek to understand the practice of the actors involved in social and legal control of drug use and to elucidate the dynamics of negotiations of criminal charges against users, in light of the debate on the changes brought about by new legislation. There has been a reduction in the number of criminal charges related to drug use, something which cannot explained by legal changes alone by the notion that this crime has gained new interpretation. We argue here that the lack of interest in criminal charges for drug use has left it in the hands of the military police who ostentively patrol city streets. They have gained an implicit mandate to negotiate whether users are arrested or not, and even acquire influence over what type of penal classification is imputed. The imprecise nature of the legal criteria employed to distinguish users and dealers, 
together with the immense disparity in the sentences given for these crimes which the new law accentuates, contribute to informal negotiation of greater or lesser charges and reifies police stereoptypes, favoring arbitrariness. This indefinition is not a result of imprecise law, but of the empirical impossibility to draw a clear-cut line between types of classifications

KEYWORDS: drug use; new Drug Law; institutional management of conflict; social control; political commodity. 
“LA FORCE” ET “LE DÉROULEMENT”: LES EFFETS PRATIQUES DE LA NOUVELLE LOI SUR LES DROGUES À RIO DE JANEIRO

\section{Carolina Christoph Grillo, Frederico Policarpo et Marcos Veríssimo}

L'article présente une analyse des effets de la nouvelle loi sur les drogues, sur la répression légale à la consommation de substances illicites, et la procédure formelle des cas envoyés au systéme de justice criminelle. On a cherché à comprendre les pratiques des acteurs intervenants dans le contrôle social ou légal de l'usage de drogues et élucider les dynamiques des négotiations dans le processus d'incrimination des utilisateurs, à la lumière du débat autour des changements apportés par le nouveau diplôme légal. On a observé une réduction du nombre de cas qui sont envoyés au système comme étant de l'utilisation de drogues, ce qui ne serait pas expliqué seulement par le changement de la loi, mais par l'interprétation selon laquelle ce crime aurait été altéré. Nous argumentons que l'indifférence avec le processus légal de ce type de crime aurait laissé son administration comme tâche à être accomplie par les policiers militaires qui font la surveillance ostensible dans les rues, qui ont gagné une autorisation implicite pour négotier l'orientation ou non de l'utilisateur jusqu'au comissariat et même influencer le type pénal où il sera classé. Le manque de précision des critères légaux pour distinguer les utilisateurs des narco-trafiquants, ajoutée à l'immense disparité entre les punitions prévues pour ces crimes là - soulignée à cause de la nouvelle loi - , contribuerait pour la négotiation informelle de la plus sévère ou moins sévère punition des individus et traite les stéréotypes policiers, favorisant ainsi l'arbitrarité. Cet indéfinition ne serait pas le résultat d'un manque de précision de la loi, mais plutôt de l'impossibilité empirique de la réalisation d'une sélection précise entre ces classements.

MOTS-CLÉS: l'usage de drogues ; la nouvelle Loi sur les Drogues ; l'administration institutionnelle de conflits ; le contrôle social ; la marchandise politique. 